\section{La enseñanza del diseño a través del Diseño Social y las nuevas tecnologías}

Guillermo Sánchez Borrero *

Resumen: La enseñanza del diseño debe ajustarse a las realidades del estudiante actual, transformar el pensamiento del docente diseñador, de emisor de conceptos básicos y fundamentos en un proveedor de medios para estructurar la experiencia a través de casos y proyectos, para que el estudiante despierte su capacidad de aprender y desarrollar habilidades como la planificación y la creatividad. La estrategia es canalizarlo a través de proyectos de Diseño Social para grupos vulnerables, con el objetivo de despertar el interés por la sociedad y lograr que los estudiantes salgan de su burbuja tecnológica y zona de confort. Todo esto con el trabajo planificado del uso de la tecnología y nuevos medios cercanos a los estudiantes, y lograr persuadirlos a su adecuado uso y aplicación, logrando así vincular los proyectos académicos como motivador para el proceso de enseñanza del Diseño Gráfico y la inclusión de aplicaciones móviles como herramientas para desarrollar el método proyectual.

Palabras clave: Diseño Social - enseñanza del diseño - buena enseñanza - personalidad creadora - aplicaciones para diseñadores - pensar innovativo - resignificación de mensajes.

[Resúmenes en inglés y portugués en la página 146]

${ }^{(*)}$ Diseñador por la Pontificia Universidad Católica del Ecuador (PUCE), Diplomado en Comunicación Corporativa por la UTPL y Máster en Dirección de Comunicación Corporativa (DirCom) por la UDLA. Doctorando UP. Docente PUCE. Docente de la Maestría de Comunicación Digital en la Universidad de los Hemisferios.

\title{
Desarrollo
}

Educar es fomentar el desarrollo de un juicio independiente y la adopción de valores culturales. Un buen diseñador tiene que ser a la vez instruido y educado para ser un buen miembro de la sociedad. No se puede hablar de buen diseño si la propuesta no es buena para la sociedad (Frascara, 2018, p. 26). 
La enseñanza y el aprendizaje son conceptos fundamentales para que el docente universitario pueda llegar al nivel de compresión y aplicación del conocimiento por parte de los estudiantes, reto que cada vez es más difícil. Los estudiantes con el inmenso flujo de información, canales y medios son segmentados y aislados de la sociedad, al mismo tiempo se vuelve un factor decisivo cuando están en el aula. Pero el diseño tiene una ventaja, soluciona problemas de la sociedad y hay que saber cómo despertar el interés de hacerlo por parte de los estudiantes a través del proyecto. El rol del docente está en la organización de la complejidad y las variables que el estudiante este en capacidad de abordar según su nivel de estudios.

Ledesma (2010) ante el agobiante enfoque del Diseño Gráfico como un promotor del consumo, propone llevar el punto de vista hacia el triángulo performativo que orienta la acción de la enseñanza del diseño a: hacer leer, hacer saber y hacer hacer. La primera, hace relación a la capacidad técnica de favorecer la inteligibilidad y comprensión de textos por el usuario, que está en directa relación con la enseñanza técnica por parte del docente, apoyado siempre de bibliografía pertinente y actualizada, además del uso de herramientas 2.0 y aplicaciones para su comprensión y optimización de recursos, como se ejemplifica más adelante en el texto. El hacer saber, que permite al estudiante determinar los canales apropiados para transmitir el mensaje gráfico y no necesariamente desde una "moda" del medio, que determine la propuesta de diseño, que además no resulte apropiada ni cumpla con las expectativas del usuario; por ejemplo, a inicios de los 2000 la creación de páginas web sin discriminar el uso y función que estas tendrían, luego a finales de está década las redes sociales empezaron a reemplazarlas, dejando en desuso a las páginas web, y en la actualidad el uso de aplicaciones para dispositivos móviles. Así mismo con la aparición de dispositivos digitales de lectura se preveía la desaparición del papel; Mario García, pionero en el cambio de soporte análogo a digital se percató de que no sería así, sostiene que "el diseño en la era digital se basa en las personas, no sólo en los dispositivos". (www. garciamedia.com.ar) Y si estos son seleccionados debe ser con un fundamento basado en el análisis de usuario.

El tercer aspecto que hace referencia Ledesma (2010) es el hacer hacer, que toma como preocupación la interpretación de la acción social del diseño, en términos de beneficioso o nocivo, y propone la existencia de una tensión ideológica. Tensión que se aborda en este documento que toma en cuenta la correlación de las tres acciones en la enseñanza y el papel del docente para con los estudiantes, motivarlos a diseñar más allá del ámbito comercial y en un equilibrio con las nuevas tecnologías y las necesidades de las personas en un entorno social.

\section{El diseño social como detonante de aprendizaje}

El punto de partida para este documento es el concepto de Diseño Social, entendido como un "conjunto combinado de procedimientos con los que se plantean soluciones innovadoras que favorecen el bien común. El diseño social está basado en la creación de soluciones y no en la creación de nuevas necesidades de consumo" (Hidalgo en disenosocial.org, 2013). Está enmarcado en la creación de nuevas formas de comunicación, de interactuar e 
intercambiar para construir propuestas de calidad. En este sentido Manzini (2015) considera el concepto de la innovación social en el diseño, que no es lo mismo que lo dicho en diseñosocial.org pero se relaciona ya que el diseño social al integrarse con la innovación social en el diseño puede lograr mejorar la creación de redes sociales a través de la producción de contenidos por medio de nuevas plataformas digitales, redes sociales, Apps, etc., que se vinculan directamente al contexto de los estudiantes universitarios. Con el objetivo de dar sentido a las cosas que se diseñan y crear nuevas entidades significativas, "el diseño se convierte en un productor de sentido... y, en consecuencia, en la generación de calidad, valores y belleza" (Manzini, 2015, p. 45).

Gary Fenstermacher (1989) aborda varios de los conceptos mencionados y propone el de "la buena enseñanza", definido como la enseñanza que alcanza el éxito y que es buena al mismo tiempo, considerando la palabra buena como una fuerza tanto moral como epistemológica. La buena enseñanza en el sentido moral hace referencia a las acciones morales que puede tomar el docente para que los estudiantes desarrollen principios, además epistemológicamente que estas acciones sean racionalmente justificables y dignas de que el estudiante conozca y entienda. Ledesma (2010) cita a Bourdieu para referirse a los distintos modos de enfocar la profesión y recalca que el diseño "es una profesión ejercida por diversos actores, en diversos medios, en diferentes contextos, con diferentes coerciones y libertades" (Ledesma, 2010, p. 89).

Para lograr que el estudiante tome un rol protagónico y activo del aprendizaje, se debe establecer una Asignatura integral o integradora, con otras disciplinas en un compromiso colectivo. Buscar en los escasos recursos que caracterizan a los problemas sociales un insumo de diseño, que se vuelvan requerimientos y mediante la investigación se pueda estar en la posición del usuario para reconocer lo deseable y no deseable. Coincidiendo con lo que sostiene Schön,

Un diseñador juega con variables, reconcilia los valores en conflicto y transforma los impedimentos. Se trata de un proceso en el que, aún a sabiendas de que unos productos diseñados pueden ser mejores que otros, no existe una única respuesta válida (1998, p. 49).

Además, sumar el factor creatividad como una característica que se debe formar en los estudiantes, el diseño social no debe ser de baja calidad por no ser comercial, debe tener todas las características y niveles de eficacia, estética y utilidad. Marina y Marina (2013) dicen que "lo que concede valor a la creatividad es el valor del proyecto que se va a resolver creativamente" (p. 12), considerando su definición de creatividad "como una cualidad de todo talento, de toda inteligencia triunfante" (p. 13) y que los problemas se pueden resolver heurísticamente.

El proceso de enseñanza - aprendizaje de los diseñadores comprende varios aspectos para lograr que la transmisión de información del docente sea relevante y que el estudiante desarrolle la capacidad de aprender, cómo aprender y habilidades básicas como la planificación a través del proyecto. Por un lado la investigación de las necesidades de las personas, analizar las diferentes variables que están alrededor de ellos, con enfoques: centrados en las personas, donde se considera a las mismas para cada una de las decisiones; participati- 
vo, donde se integra al usuario durante todo el proceso en especial para la definición de la solución, concepto en estrecha relación con el diseño social; finalmente el enfoque basado en evidencias donde el docente debe enseñar al estudiante a identificar información confiable y en el caso de no existir, construirla (Frascara, 2018).

Otro aspecto es la capacidad de construir un mensaje gráfico, lograr concebir y articular un enunciado comunicacional que puede ser o no eficaz dependiendo del acercamiento a la realidad que desarrolle el docente y el estudiante para representar una solución impreso o digital (Zimmermann, 2002). Soluciones que pueden formar sistemas morfológicos que permiten abordar diferentes niveles de complejidad mediante el diseño de conjuntos de piezas que sean posibles de leer de forma unitaria, pero sin perder su particularidad. También pueden formar sistemas conceptuales para desarrollar discursos complejos y dinámicos para lograr un mayor grado de independencia entre sí en relación con los sistemas morfológicos (Mazzeo, 2017). Con el fin académico de medir el nivel de eficacia y desempeño de las ideas materializadas en estos sistemas gráficos, por ejemplo en aumentar la capacidad de las personas para entender qué debe considerar ante una emergencia (como es el caso que se muestra más adelante), disminuir el tiempo de encontrar un sitio dentro de un espacio arquitectónico o urbano, aumentar el nivel de comprensión de operaciones aritméticas, reducir el riesgo a cometer errores al realizar una actividad o armar un objeto, son entre otros casos proyectos que se desprenden de la academia.

Un tercer aspecto y además fundamental y característico de la disciplina es el momento heurístico, desde la definición de Breyer "como teoría del pensar innovativo, entronca con una teoría psicológica filosófica de la invención” (2007, p. 19). Permite resolver problemas que pueden despertar un mayor interés en los estudiantes, con un desarrollado talento y un pensamiento heurístico, capaces de resolver problemas que más les interesa o les angustia y que necesitan desarrollar un alto nivel de pensamiento creativo que logre un equilibrio perfecto entre la solución de problemas rutinarios y complejos dentro del ámbito social (Marina y Marina, 2013).

Es interesante la definición de Marina y Marina sobre la creatividad, que rompe con el pensamiento popular de la inspiración divina, habla de que para ser creativo las personas (el diseñador para el caso) deben ser inteligentes y cultas, que "la creatividad es una cualidad de todo talento, es decir, de toda inteligencia triunfante" $(2013$, p. 13) y que existen dos tipos de creatividad, la general que sirve para vivir inteligentemente y la especializada, que es dependiente de un dominio, que puede ser el diseño de comunicación gráfica. En el diseño social, es la oportunidad de los diseñadores de vincular dichos tipos de creatividad con la realización de un proyecto social inteligente, para construir con el estudiante una personalidad creadora en conjunto con el docente integrando recursos intelectuales, emocionales y ejecutivos (Marina y Marina, 2013).

Un cuarto aspecto tiene que ver con el desarrollo de la personalidad creadora, identificar de donde vienen las ideas, que no es más que la agilidad mental, entendida como la capacidad de moverse con soltura en el espacio mental (Marina y Marina, 2013) que se construye en el estudiante por medio de la semiótica y la capacidad de relacionar analogías complejas y uso adecuado de metáforas. El diseñador en su formación debe sensibilizarse en la comprensión de las imágenes y entender que son parte de un contexto social y político, para poder acercarse al pensamiento de un grupo social y lograr diseñar mensajes 
gráficos apropiados. Se debe tomar en cuenta que "cada imagen y objeto que un grupo social utiliza es una puerta de acceso para entenderlo. Y permite llegar a la forma en que la identidad se materializa e interactúa con su mundo" (Guerrini, 2017, p. 129).

Para la materialización de las ideas, se hace uso de la semiótica en la generación del partido conceptual, que "no es la mera constatación o evidencia de un estado de cosas. Los partidos no son objetos que existen y debe ser descubiertos, sino que son realizaciones que vinculas elementos a través de una particular mirada" (Carpintero, 2009, p. 15). El partido conceptual es una guía que indica el camino del diseñador para verificar si la propuesta de diseño es pertinente y logra una producción de sentido (Verón, 1987; Sexe, 2001) que amplíe en el usuario la capacidad de reconocer un discurso a través del diseño gráfico por medio de un manejo perfecto del: representamen, que es la parte técnico - pedagógica de la propuesta, es decir para la necesidad que se requiere resolver; el objeto, que es la pieza a diseñar, con todos sus recursos de producción y la concepción de la forma metafórica; finalmente el interpretante, el más importante, el usuario, que hace que el diseño tenga una razón de existencia disciplinar. Para lograr una semiosis social, como lo denomina Verón (1987).

Para que el estudiante tenga un nivel de aprendizaje de la estructura proyectual del diseño que se ha tratado en los párrafos anteriores, se debe empezar por el docente, pues tiene que ser un proveedor de medios para estructurar la experiencia y la asignatura de Taller de diseño y los proyectos sociales son los ideales para que esto ocurra, así el docente puede y debe trasmitir virtudes morales como: honestidad, respeto, aptitud flexible y fiabilidad para levantar información y al relacionarse con un usuario vulnerable. Por otro lado, las virtudes intelectuales como: humildad, creatividad, aptitud reflexiva e imparcialidad, que logre transferir al estudiante en el momento de realizar las propuestas de diseño. Y por qué no incluso llegar a ser un docente memorable, tomando el concepto de Philip Jackson. Considerando la definición de diseño que hace Heskett como "una de las características básicas de lo humano y un determinante esencial de la calidad de vida. Afecta a todas las personas, en todos los detalles de lo que hacemos cada día" (2005, p. 4) se vincula al planteamiento del método para enseñar diseño por medio de temas sociales, llamado Diseño Social. Que despierten este sentimiento humano en los estudiantes para mejorar la calidad de vida de las personas, y entiendan que es más que un aprendizaje académico.

Ledesma (2018) aborda el concepto de Diseño Social como la investigación propia de necesidades que tiene la humanidad, específicamente con grupos vulnerables de la sociedad que además potencian sus riesgos debido a la convergencia de fenómenos sociales como: enfermedades, vejez, violencia de todo tipo o riesgos naturales del que son consientes los pobladores de ciertas zonas de riesgo. $\mathrm{Al}$ abordar este tipo de temas para los proyectos, se lo hace de forma interdisciplinaria y con diferentes sectores gubernamentales y privados para lograr una extensión amplia destinadas a toda la sociedad, así como para agrupaciones que no han sido consideradas, tomando en cuenta la característica que deben tener, "el convencimiento de una realidad posible de cambiar" (Ledesma, 2018, p. 17).

Frascara (2018) corrobora la necesidad de que el aprendizaje debe estar basado en problemas, dejar de hacer ejercicios sin sentido ya que los estudiantes pierden interés al no ver resultados, cuando simplemente se pasan resolviendo variables y ejercicios aislados. Sostiene que "la universidad debe aspirar a formar a los estudiantes más allá de los re- 
quisitos mínimos del ejercicio de la profesión... deben también estar preparados para el aprendizaje futuro" (Frascara, 2018, p. 57) que logren además enfrentar situaciones con responsabilidad social y gusto por hacerlo. El punto de partida es identificar los grupos sociales que necesitan de la intervención del diseñador, Ledesma (2018) propone seis zonas vinculadas con dichas necesidades: Generación de la conciencia social, identificar grupos aislados por motivos no económicos como incapacidades físicas o mentales, ofrecer los servicios profesionales a personas que no pueden pagarlo, orientación para desarrollos productivos nacientes, instrumentar la construcción de identidades y, potenciar la calidad de vida y bienestar social.

Marina y Marina (2013) coinciden con la estrategia de educación por proyectos como un medio que permita al estudiante tome posesión de su inteligencia, pueda configurar su autonomía y tenga la capacidad de imaginar posibilidades en relación con la realidad del usuario para quien diseña. En una conferencia de Norberto Chaves en la Universidad de Palermo decía que, si los diseñadores se quedan sin metáforas o pierdan la capacidad de metaforizar los fenómenos, están perdidos, y eso pasa cuando dejan de ser cultos. Se refiere justamente a la pérdida de la capacidad de imaginar posibilidades, posibilidades que se surgen de situaciones reales de una sociedad vulnerable que quiere vivir en libertad y con dignidad.

Los proyectos que se están desarrollando en la academia, se encuentran en el marco de cualquiera de las seis zonas, aunque en la que más se a intervenido es la relacionada a los grupos sociales aislados por motivos no económicos como los grupos étnicos que existen en Ecuador y la disminución de la conservación de culturas, costumbres y tradiciones debido a la migración de los jóvenes a las ciudades y el desinterés de conservación. El ofrecimiento de servicios profesionales a personas que no pueden pagarlo fue el principio del desarrollo de asignaturas integradoras que intervengan en micro y medianas empresas, que nunca consideraron el diseño como un gestor dentro de la empresa, incluso se ha logrado trabajar con el sector gubernamental del Ministerio de Industrias y Productividad (MIPRO).

Por otro lado, se encuentran los proyectos destinados al bienestar social, para lograr el empoderamiento de la disciplina del diseño como gestor de cambios sociales, además logra que los estudiantes y docentes sean una pieza fundamental para que el sistema funcione de forma adecuada y metodológicamente guiada.

$\mathrm{Al}$ abordar temas sociales y pedagógicos, la universidad, el docente y el estudiante se vuelven parte activa de la sociedad, mediante un enfoque participativo con el usuario, que más allá de estudiarlo e investigarlo lo invita a participar en el proceso del planteamiento del problema, el desarrollo de la propuesta de diseño e incluso en la producción de piezas si fuera el caso. En la Carrera de diseño de la PUCE se está trabajando esta idea de ejes temáticos coyunturales sociales, se lo ha denominado Diseño $\mathrm{x}$ (por) que busca relacionar al cuerpo docente y estudiantes en las diferentes asignaturas con los problemas cercanos del país, por ejemplo, se han abordado temas con los refugiados, la migración, el medio ambiente y la niñez (Ver Figura 1). Quizá lo que falta al programa para que termine de consolidarse es el desarrollo claro del proyecto y la investigación y por su puesto entender a quién se está enseñando. 


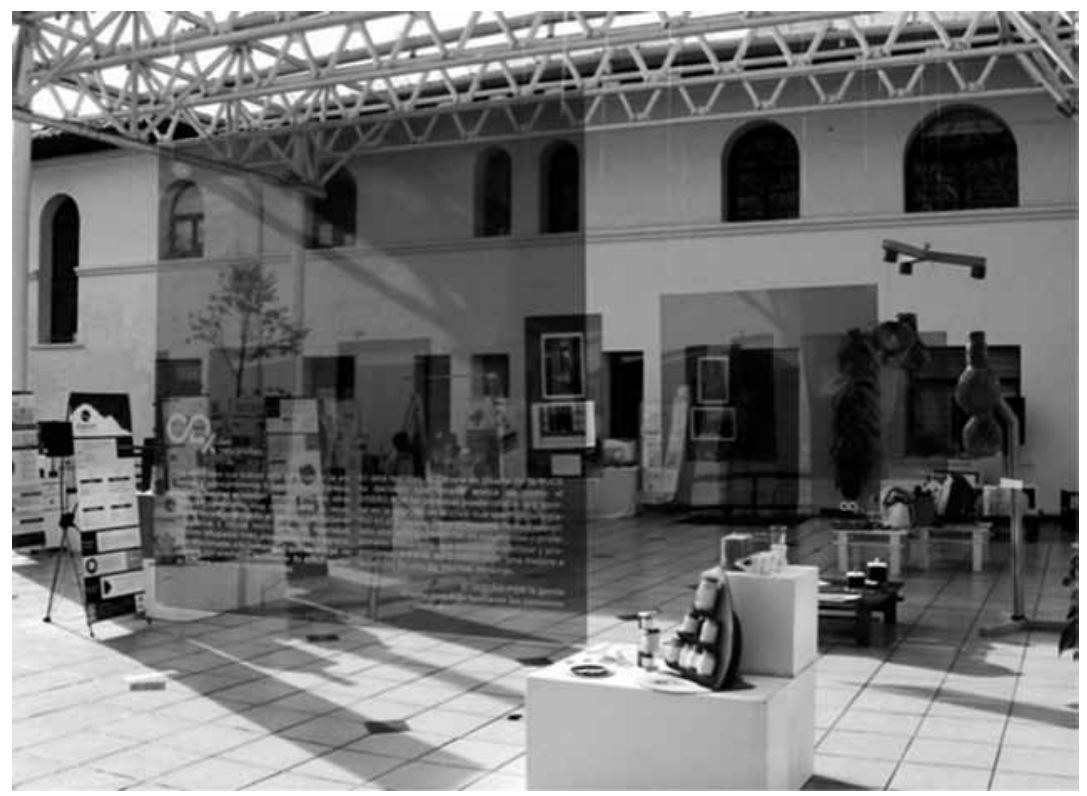

Figura 1. Presentación de proyectos de Diseño x Refugiados.. Fuente. Carrera de Diseño de la PUCE.

\section{La creatividad como puente entre docente y estudiante}

Cuando se pregunta si se conoce a la persona que recibe el conocimiento se refiere a los estudiantes, es importante entender su imaginario, relación con su entorno y la sociedad en la que viven. Serres (2013) explica que para enseñar se debe conocer al nuevo estudiante, su tiempo y contexto. Afirma que los nuevos estudiantes deben cambiar al mundo, y por medio de la Universidad lo pueden lograr a través de un portavoz que sería la figura del docente. Aprender en nuevas condiciones, aprender haciendo algo más por la sociedad y vinculado a otras disciplinas por medio de un trabajo colaborativo basado en retos.

Serres es crítico con la vida virtual que llevan los niños y jóvenes, sostiene que los métodos de búsqueda en Wikis y redes sociales "no estimulan las mismas neuronas ni las mismas zonas corticales que el uso del libro, de la tiza o del cuaderno... No conocen ni integran, ni sintetizan la información" (Serres, 2013, p. 21). Esta realidad hace que los estudiantes no se preocupen al menos por tomar apuntes, ni bocetar ideas para recordar a manera de mapa mental, incluso genera la desatención en las clases, están físicamente pero no mentalmente.

Para eliminar esta frontera que se ha creado entre la enseñanza y los estudiantes considero que la alternativa es no prohibir el uso de las nuevas herramientas tecnológicas y de comu- 
nicación, si no aprender a utilizarlas de forma complementaria a la formación académica formal para agilitar el proceso de diseño, lograr una sincronía entre las cuatro esferas o perspectivas que caracterizan el cambio constante de esta era, consolidar: herramientas y máquinas, información, medios de comunicación y psicología humana (Gardner y Davis, 2014). Esto permite disponer de más tiempo para entender y relacionarse con el usuario. Que los estudiantes estén por un lado motivados a proponer soluciones de diseño con un fin real ante la población y por otro, que encuentre en la tecnología su aliado estratégico. Gardner y Davis (2014) con respecto al tema de las nuevas generaciones las caracterizan como una Generación App, dicen que la naturaleza del ser humano no ha cambiado en su parte fundamental, "que las tecnologías digitales han reconfigurado significativamente la Identidad, la Intimidad y la Imaginación durante las últimas décadas” (p. 17). La relación entre las redes sociales y los temas de los proyectos pueden motivar a modificar el comportamiento del grupo de estudiantes, cambiar las fotos grotescas y sin valor, por fotos y publicaciones de lo que están haciendo por la sociedad.

Ledesma (2010) en basada en su experiencia docente en la universidad argentina propone el debate de cuatro elementos que se articulan en la enseñanza: las tipologías, la comunicación y la recepción, los derroteros de la imagen y la estrategia comunicacional. Estos elementos resultan una estrategia pedagógica para relacionar el interés del desarrollo de temas de diseño social y las nuevas tecnologías. Las tipologías son una valiosa fuente de información para entender cómo otros diseñadores solucionaron problemas similares a los planteados en clase, el objetivo no es reproducir la tipología, sino analizar en profundidad: los soportes y sistema de impresión, medios digitales e interacciones que generan los usuarios.

El segundo recorte pedagógico que propone Ledesma (2010) tiene que ver con el alcance comunicacional que tenga la propuesta de diseño y la necesidad de pensar en la comunidad de receptores, de entender su entorno e imaginario y si al entrar en contacto o interacción, serán capaces de satisfacer su necesidad de forma ágil e intuitiva. El docente debe lograr que el estudiante comprenda que el receptor "no es una entidad aislada que está esperando al final de la línea que le llegue el mensaje, sino que conoce otros textos y tiene una posición en relación a ellos" (Ledesma, 2010, p. 94). Lo mismo que pasa al confrontar al usuario con la pieza diseñada, se debe entender que, así como el estudiante tiene acceso a una infinita cantidad de información, los usuarios están saturados de dicha información y pueden incluso opinar al respecto en un sentido amplio del conocimiento disciplinar del diseño, no son ingenuos, son activo y tienen la capacidad de criticar y comparar con otras alternativas que quizá estén mejor resueltas. Por está razón el diseñador debe tener un alto nivel de cultura y calidad de información para que pueda producir de forma coherente, para tener un basto banco de relaciones metafóricas y por consecuencia conceptos de diseño posibles de persuadir y provocar efectos en el usuario.

El tercer recorte tiene que ver con la producción gráfica que pueda tener el estudiante diseñador con la tutela del docente. La calidad y pertinencia de representaciones formales, códigos de percepción y efectos sobre los imaginarios de las personas de una sociedad vulnerable específicamente.

La estrategia comunicacional es el cuarto recorte pedagógico, que considera las condiciones de relación entre el estudiante y su entorno social y tecnológico que varían las 


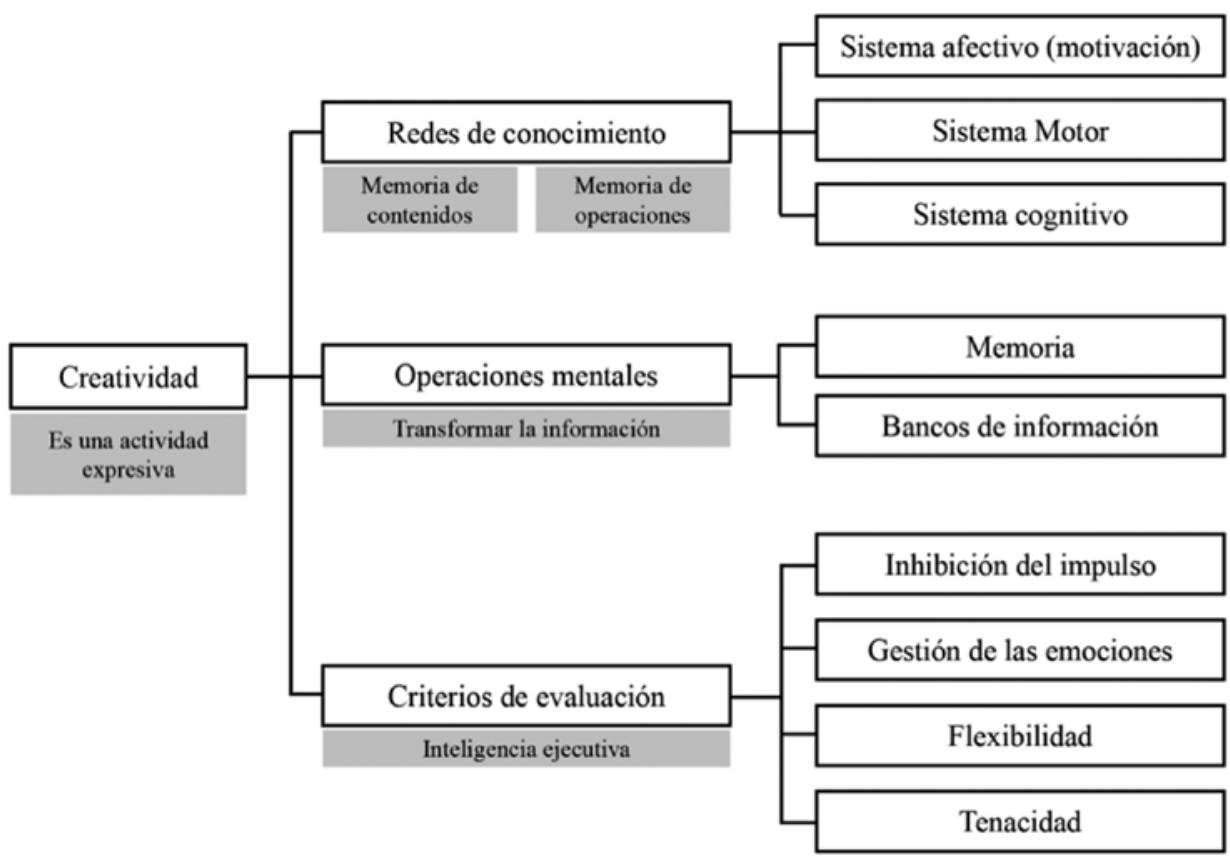

Figura 2. Adaptación del aprendizaje y los hábitos de Marina y Marina 2013.

opciones del desarrollo de las propuestas de diseño. El adecuado estudio y correlación que prepare el docente de forma estratégica puede persuadir al estudiante a explorar las tecnologías de la información, dispositivos y aplicaciones, de forma académica y casi profesional que logre una estructura de la morfología gráfica adecuada pensando y diseñando al receptor de la propuesta, a través del dominio de competencia de diferentes campos como creencias, valores, opiniones, y la intencionalidad del docente, estudiante y por su puesto el usuario (Ledesma, 2010).

Marina y Marina (2013) abordan el término de la creatividad y lo relacionan con los hábitos: motivacionales, cognitivos y operativos, que se pueden considerar en la correspondencia de la enseñanza del diseño. Despertar una pasión por diseñar soluciones gráficas que le sirvan a la sociedad y además hagan usos de los dispositivos y medios digitales que están a su alcance y son parte de su vida. En la Figura 2 se resume la relación del concepto de creatividad y las diferentes secciones que se puede abordar en la enseñanza de este concepto. Se parte del interés por los hábitos cognitivos que trata de la importancia de tener 
un basto conocimiento de la sociedad, salir del aislamiento de lo efímero y utilizar canales como redes sociales para ver el mundo y su realidad, despertar una sensación de dolor por la persona que está a su lado y ampliar el imaginario en los estudiantes.

Se entiende la creatividad como una expectativa expresa que sirve para fomentar buenas ideas que son alternativas de un cambio sensato de una situación en un momento adecuado y factiblemente aplicable, que se abarca tres instancias: 1) Las redes del conocimiento generadas a través de la exploración y estado de alerta por la información de contenidos y de las experiencias de vida que puede transmitir el docente al estudiante desde su experiencia de la vida profesional, para estimular tres sistemas: afectivo o motivacional que se relaciona con el Diseño Social. El sistema motor, que comprende las habilidades de los estudiantes o el resaltar de éstas por medio de actitud de poder hacer las cosas. Finalmente, el cognitivo que está influenciado por la calidad de conceptos, imágenes y recuerdos significativos que el estudiante este en capacidad de conectar entre si y logre codificar la información y pueda proyectar una solución gráfica. 2) Las operaciones mentales, se refieren a la búsqueda adecuada de la información e investigación, en la memoria siempre y cuando el estudiante tenga un bagaje cultural que le permita aportar con el proyecto, proveniente de su vida diaria: noticias, música, cine, teatro, etc. Otra forma de obtener la información es a través de los diferentes medios bibliográficos y digitales que son más cercanos a los estudiantes universitarios, pero el papel del docente es saber guiar para está búsqueda caso contrario ocurre lo que dicen Marina y Marina "un burro conectado a internet sigue siendo un burro, mientras que una personalidad creativa conectada a internet aumenta su capacidad creadora" (2013, p. 193). 3) Los criterios de evaluación, tan importantes en el diseño porque permiten medir la incidencia de la pieza propuesta en relación con el usuario. Es una inteligencia ejecutiva que se necesita para evitar que el proyecto fracase. Se puede realizar la evaluación de los proyectos desde la inhibición del impulso, la gestión de las emociones, la flexibilidad y la tenacidad. Con estos aspectos se pueden elaborar rúbricas de evaluación o planificación de esquemas, guiones y preguntas para realizar investigación cualitativa con el usuario.

Tanto la selección del tema social como el despertar en la creatividad de los estudiantes de Diseño Gráfico deben tener un resultado y servir a la sociedad, Guerrini (2017) habla sobre los poderes que tiene el diseño, poderes que son capaces de intervenir en el imaginario, en el deseo, y en el grado de recordación de dicha sociedad. En relación con lo desarrollado líneas arriba con respecto a la creatividad por José Antonio y Eva Marina, se destaca el poder de imaginar, que corrobora el origen de las buenas ideas, no de iluminaciones ni inspiraciones divinas, sino, como define Guerrini como un estado de sensibilidad "a las cosas que están latentes en la comunidad. Esto es detectar, recopilar y organizar los fragmentos que se mezclan en la realidad social, en los discursos e historias, tratando desde la acción interpretar que sucede alli” (Guerrini, 2017, p. 66).

El poder de generar deseo es significativo en la enseñanza - aprendizaje, saberlo utilizar implica que los estudiantes deben conocer su potencial y manejarlo de forma consciente y ética, es influyente en el comportamiento positivo o negativo en una sociedad vulnerable, ya que se pueden mal interpretar mensajes y códigos y obtener resultados opuestos a los objetivos planteados. Guerrini sostiene que: 
El diseñador es capaz de influir en el espectador (usuario) mediante la conexión de sus mundos sensoriales; entre la razón, percepciones y emociones, por medio de movilizar significados, jugando con los sentidos imaginando realidades y posibilidades; interpretando escenas; creando esperanzas y deseos; dando instrucciones a esos deseos y enseñando o despertando al deseo (2017, p. 69).

\section{La era 2.0 y Apps en la enseñanza del Diseño}

Para explicar esta unión entre los temas sociales como eje de la buena enseñanza y el uso de las tecnologías, en los últimos semestres en la carrera de Diseño de la PUCE se ha trabajado con sistemas de información teórica de diseño que se encuentra en línea, es el caso de la plataforma Material Design, ahora Material.io, "un lenguaje visual que sintetiza los principios clásicos del buen diseño con la innovación de la tecnología y la ciencia” (https:// material.io/design/) esta plataforma es una "guía de estilo que Google lanzó en 2014 con el objetivo de unificar criterios estéticos y funcionales -basados en procesos y experiencias en torno al diseño de Google- para la creación de la interfaz de sistemas operativos" (https://graffica.info) mediante metadatos que los usuarios generan al realizar búsquedas y uso de dispositivos.

Material.io esta creado principalmente para productos digitales y experiencias de usuario, pero no es un limitante para la aplicación en productos impresos ya que las herramientas que ofrece están relacionadas con el método proyectual que toda propuesta de diseño contempla, para lograr productos de diseño más eficientes, alineados a las necesidades de los usuarios. Incluso se puede proponer el desarrollo de más plataformas de este modelo para los diferentes sistemas de comunicación gráfica. La plataforma presenta varias alternativas a manera de estudio sobre cómo los usuarios hacen uso de las aplicaciones en los dispositivos y pantallas, tiene como base los fundamentos del diseño gráfico y hace su propia lista: ambiente, composición, navegación, color, tipografía, iconografía, forma, movimiento, interacción y comunicación.

Como ejemplo de la versatilidad de las herramientas está el sistema estilizado de íconos que responden al imaginario y percepción de los usuarios. Así mismo el color que plasman los conceptos de psicología y teoría del color en la usabilidad, incluso permiten medir el nivel de accesibilidad que da a los usuarios, dicha selección (Ver Figura 3).

En el apartado de tipografía, los estudiantes pueden encontrar todo lo relacionado a la tipografía, sus propiedades, comportamiento y legibilidad en tiempo real según el caso de necesidad de aplicación que el proyecto requiera. Incluso aborda el comportamiento de los párrafos para que sean amigables al lector y cumplan adecuadamente con la parte técnica dentro del lenguaje gráfico de cualquier propuesta diseñada.

Las herramientas digitales que están más cercanas a los estudiantes universitarios se pueden optimizar si se relaciona con las asignaturas desde la enseñanza de los fundamentos del diseño hasta los proyectos complejos como los de titulación que manejan muchas variables. Los estudiantes pueden tener un proceso creativo y morfológico pensado en el usuario y en lo que hace día a día, considerando datos reales que incluso pueden fomentar 

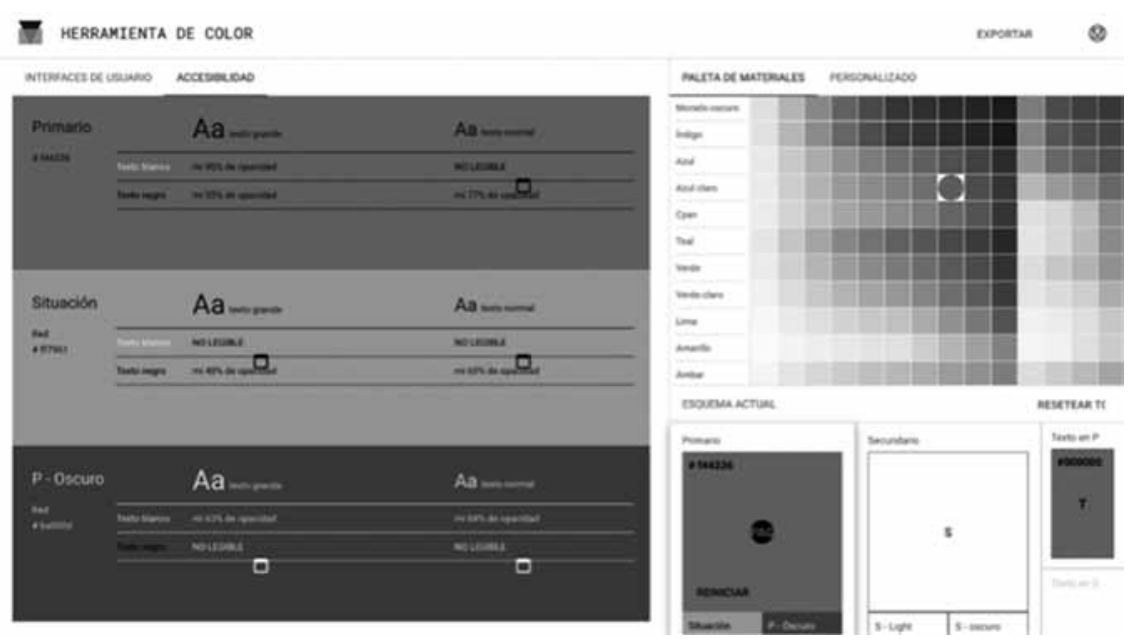

Figura 3.
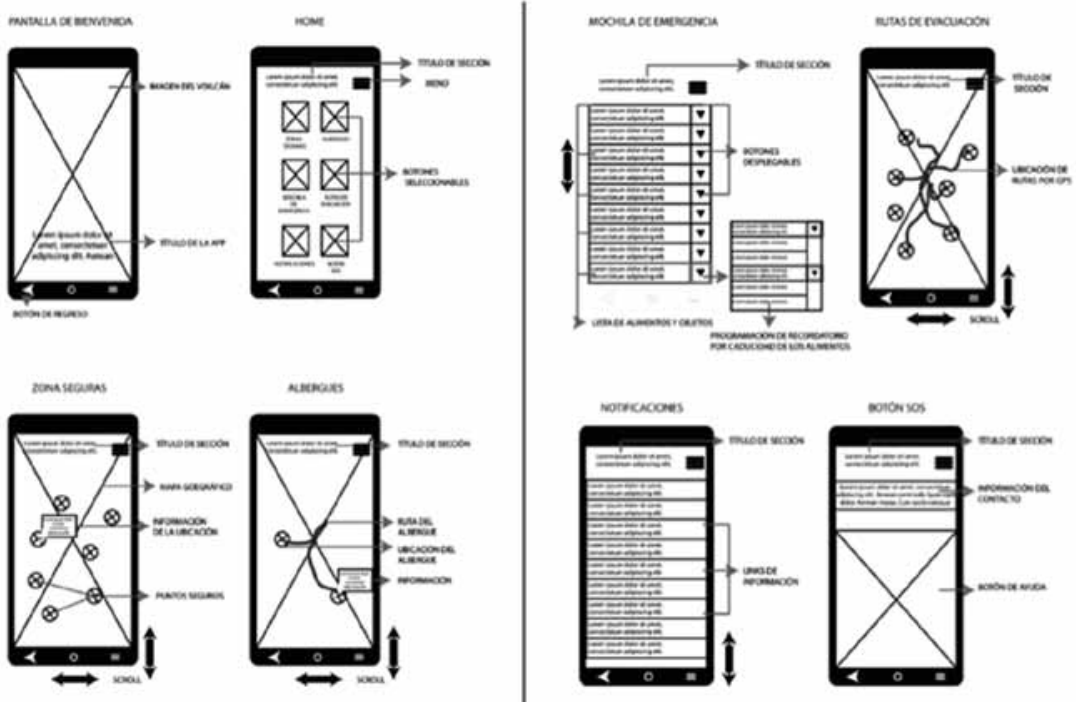

Figura 4.

Figura 3. Medición de accesibilidad del color. Fuente: https://material.io/tools/color/\#!/?view.left=1\&view. right $=0$ \&primary.color $=0088 d 1$. Figura 4. Estructura de la aplicación. Fuente: Trabajo de Titulación de Andrés Fernández. PUCE, Repositorio Tesis Grado y Posgrado. 
la investigación especializada y segmentada según criterios: geográficos, demográficos y socioeconómicos. Incluso profundizando en la investigación de las "características psicológicas y culturales, tales como temperamentos, valores culturales, apetitos y expectativas. Estas dimensiones menos cuantitativas consideran las maneras en que diferentes grupos conciben las nociones de economía, lujo, eficiencia, seguridad, belleza, etc." (Frascara, 2015, p. 29).

En lo personal he desarrollado esta lógica de fusión entre el tema del Proyecto de Titulación y las tecnologías, llegando a proyectos que parten de una necesidad social con un alto impacto de medición. El caso de estudio fue el diseño de una aplicación para contribuir a la reducción de la vulnerabilidad de los habitantes de una zona cercana al del volcán Cotopaxi ante una posible erupción. Este proyecto es un ejemplo de como se puede a través del diseño social estimular al estudiante para ayudar a la sociedad ante un peligro inminente y hacer uso de las herramientas digitales para lograr un proyecto fiable y pensado en el usuario.

En la Figura 4 se puede visualizar la aplicación del conocimiento de la herramienta Tipos de navegación "La navegación es el acto de moverse entre las pantallas de una aplicación para completar tareas. Se habilita a través de varios medios: componentes de navegación dedicados, integración del comportamiento de navegación en el contenido y posibilidades de la plataforma." (https://material.io/design/navigation/understanding-navigation. html\#types-of-navigation). Permite su aplicación a la arquitectura de la información y el análisis de la navegación lateral, para moverse en el mismo nivel de jerarquía; la navegación hacia delante que se refiere a moverse entre pantallas en niveles consecutivos de jerarquía y, la navegación inversa que es el desplazamiento hacia atrás a través de pantallas cronológica o jerárquicamente. (https://material.io/design/navigation/understandingnavigation.html\#types-of-navigation). La plataforma muestra ejemplos y permite probar la navegación del proyecto. El manejo de está herramienta agilita el proceso de diseño en los estudiantes, pueden dedicar más tiempo al factor ideas y conceptos persuasivos sin invertir mucho tiempo en la dinámica de navegación que los usuarios tienen.

También se puede explorar pautas de interfaz humana para dispositivos Android o iOS para un control del diseño de la aplicación y el dispositivo, que determinará un nivel de usabilidad y cumplimiento de objetivos muy alto (Ver Figuras 5 y 6 ).

Además de la plataforma expuesta anteriormente, existe gran cantidad de aplicaciones para dispositivos móviles, en muchos de los casos los estudiantes no saben de su existencia y el uso académico que pueden tener más aun en el área de diseño. Dichas aplicaciones les permite agilitar procesos creativos y técnicos permitiendo distribuir mejor el tiempo de la elaboración y desarrollo de un proyecto.

Son varias las alternativas de aplicaciones específicas para diseño que hay en el mercado, en la parte creativa: Design Thinking Canvas, Design Thinking, Adobe Create, entre otras. Así como también las que tienen que ver con productividad: Adobe Comp, Adobe Draw, Adobe Clip y Adobe Capture, que permiten plasmar ideas que luego se llevan a un desarrollo completo en los computadores.

De las herramientas mencionadas anteriormente, una de las que se ha utilizado en las clases es Adobe Capture CC que es una aplicación para dispositivos móviles que sirve a los estudiantes como herramienta en términos de fundamentos de diseño al momento de 

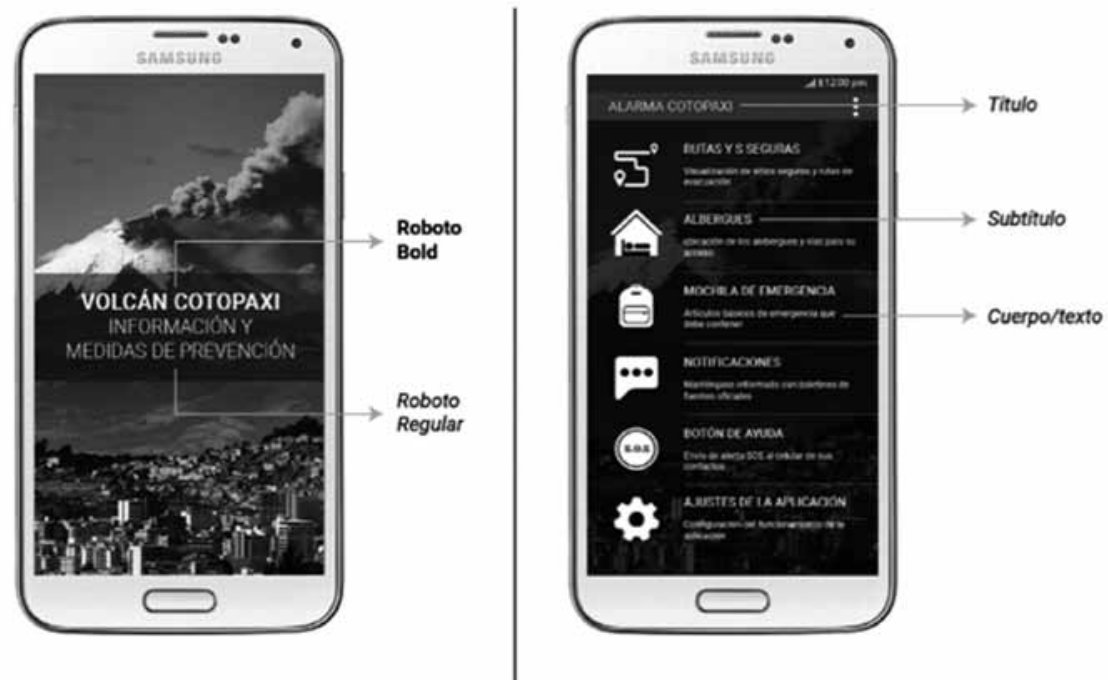

Figura 5.
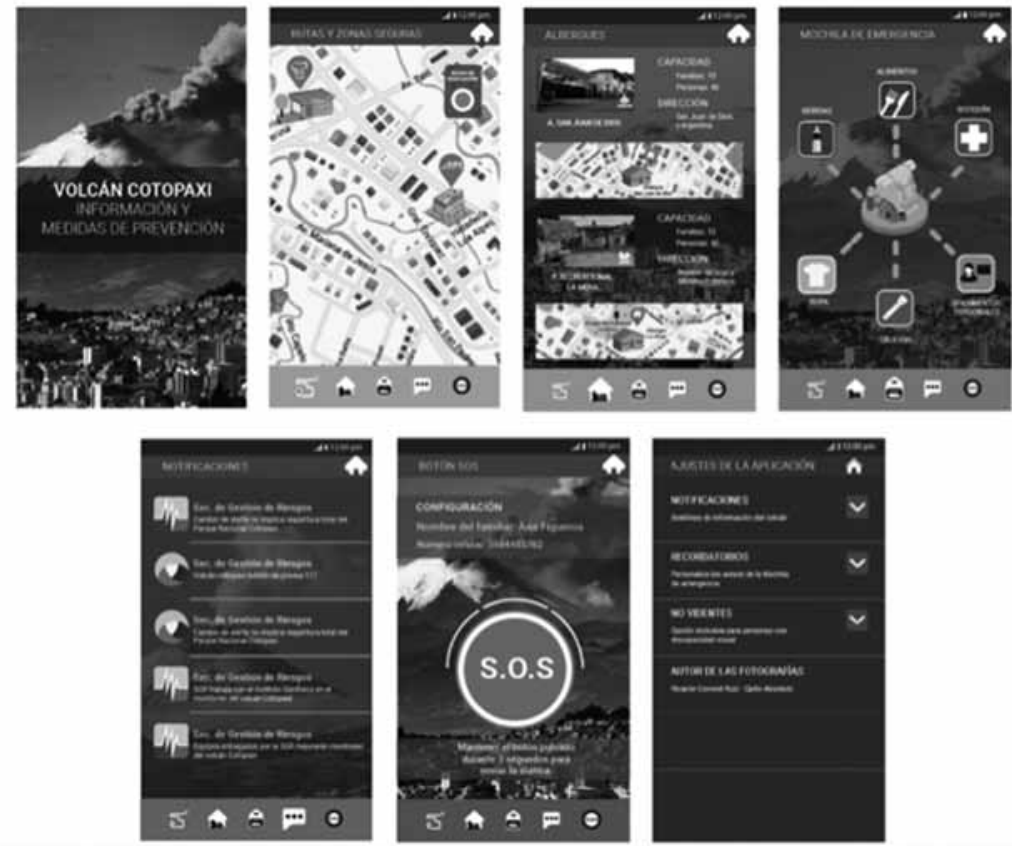

Figura 6.

Figura 5. Aplicación de la tipografía según Material Design en la App. Fuente: Trabajo de Titulación de Andrés Fernández. PUCE, Repositorio Tesis Grado y Posgrado. Figura 6. Pantallas principales de la App. Fuente: Trabajo de Titulación de Andrés Fernández. PUCE, Repositorio Tesis Grado y Posgrado. 
establecer una paleta de colores, por ejemplo, pasar del método tradicional al digital con el apartado específico Colores que captura temas de color para transformarlos en paletas personalizables (Adobe.com) tomando como principio de la composición técnica de dicha paleta, la teoría de color. Esto puede agilitar procesos de producción y uso focalizado del dispositivo. Para esto el estudiante ya debió abordar estos temas en la clase. Se puede obtener una paleta de cinco colores para un proyecto, determinado: escalas de tono, saturación, temperatura y brillo, para lograr la unidad pertinente en un sistema gráfico.

Así mismo la aplicación PANTONE Studio que permite el acceso a más de 10.000 tonos estandarizados de colores, con características como: valores de color / referencias - sRGB HEX - CMYK - Armonías (complementarias, monocromáticas, análogas, divididas complementarias, triádicas), se puede hacer uso de la cámara fotográfica del teléfono inteligente para crear muestras de color.

También visualiza los colores PANTONE en papeles y telas 3D flexibles. Los usuarios pueden desplazarse por los diseños e imágenes de los artistas organizados por PANTONE Color y seleccionar sus paletas para su uso. Tendencias del Pantone Color Institute ${ }^{\mathrm{TM}}$ (PCI). El contenido incluye artículos enfocados en las emociones, significados, psicología y contexto detrás de colores particulares (www.pantone.com).

Además de tener una herramienta de alta calidad, se evita el gasto de comprar una pantonera que normalmente ha sido exclusiva de los sitios de impresión o de grandes empresas de diseño, ahora el estudiante puede tenerla a su alcance y prepararse de forma eficiente para el mundo laboral.

Otra sub-herramienta de Adobe Capture es Tipos, que identifica fuentes tipográficas similares a las que se esta utilizando en el proyecto. "Capture utiliza la tecnología Adobe Sensei para reconocer la forma de los caracteres y sugerir fuentes visualmente similares, que después se puede guardar como estilos de caracteres" (Adobe.com, 2018). Se puede convertir en una forma dinámica y moderna de la enseñanza de la tipografía, como un complemento de la teoría impartida en la asignatura, con el objetivo de que el estudiante logre vincular el uso de su dispositivo a una tarea profesional y necesaria para su desempeño. Una fuente de información que además está constantemente actualizada es Google Design, una plataforma desarrollada por diseñadores, escritores y desarrolladores de Google. Trabajan en equipos para crear contenido y producir eventos que muestran el trabajo de diseño de Google y defienden a los innovadores en el campo del diseño. Cuenta con secciones de consulta: bibliotecas, noticias, recursos y portafolios de trabajos. Se puede suscribir para recibir información, descargarse Podcasts de las diferentes plataformas e incluso contar con entrevistas transcritas en pdf. Por ejemplo, la entrevista con el diseñador interdisciplinario Sang Mun de YAW Studio, que muestra su proyecto donde explora cómo el tipo de letra ZXX, que nació de la experiencia de inteligencia especial de Sang, ayuda a considerar la privacidad y la naturaleza de la información que da forma a la vida de la sociedad, cómo las herramientas accesibles pueden potenciar usuarios, y cómo pensar en las restricciones prácticas que todos enfrentan como diseñadores. 
En cuanto a los recursos, ofrece la plataforma de descarga de fuentes tipográficas Google Fonts, que es un directorio de fuentes tipográficas que simplifica el proceso de selección tipográfica para los proyectos, además de ser de código abierto.

Nuestro directorio de fuentes coloca la tipografía al frente y al centro, invitando a los usuarios a explorar, ordenar y probar fuentes para usar en más de 135 idiomas. Presentamos diseñadores de tipos individuales y fundiciones, brindándole información valiosa sobre las personas y sus procesos, así como también analíticas sobre el uso y la demografía. Nuestra serie de colecciones temáticas lo ayuda a descubrir nuevas fuentes que han sido examinadas y organizadas por nuestro equipo de diseñadores, ingenieros y colaboradores, y nuestra clasificación predeterminada organiza las fuentes según su popularidad, tendencias y su ubicación geográfica. También puede crear sus propias colecciones altamente personalizadas filtrando familias, pesos y scripts, además de temas de color de prueba y una copia de muestra de revisión (https://fonts. google.com/about).

Sin duda una herramienta moderna de consulta, actualizada y posible de interactuar en una clase con los estudiantes. Enseñar teoría del color, tipografía y composición utilizando los dispositivos móviles de cada uno con un fin de resolver un problema de diseño gráfico.

\section{Conclusión}

Es posible una fusión entre el Diseño Social y las nuevas tecnologías y que este modelo sirva como estimulante en la relación de enseñanza - aprendizaje. A través de un sistema colaborativo entre docente - estudiante y sociedad. Donde el estudiante sienta que lo que hace es muy importante y aporta en la mejora de la calidad de vida de las personas. A demás con el uso de los dispositivos y nuevos medios que le interesa utilizar y es muy fácil hacerlo por su cercanía con la tecnología.

Desde la más simple de las asignaturas hasta un proyecto de titulación para lograr que el docente y el estudiante sean capaces de abandonar razones propias y buscar en los otros las buenas razones para diseñar. Con esto dar fin al ritual de incautar los dispositivos móviles al inicio de la clase o controlar el uso de redes sociales. Volver a la tecnología la herramienta que permite desarrollar proyectos y ser mejores diseñadores.

La enseñanza por proyectos permite el aprendizaje en conjunto y de forma dinámica como cualquier metodología proyectual de diseño con la particularidad de enfrentar una realidad activa y práctica con el objetivo de materializar el mensaje gráfico para la mejora de la calidad de vida de los demás. El docente de diseño debe lograr que el estudiante pueda plantearse y resolver objetivos que logren: crear sensaciones y emociones, diferenciar mensajes y contenidos, definir valores y responsabilidades, visibilizar espacios y contenidos, interpretar necesidades, y resignificar los imaginarios culturales. 


\section{Lista de referencias}

Adobe.com (2016). Adobe Capture CC. Desde la inspiración a la creación de recursos. Recuperado el 30 de agosto de 2018 de: https:/www.adobe.com/la/products/capture.html Breyer, G. (2007). Heurística del diseño. Buenos Aires: Nobuko.

Carpintero, C. (2009). La dictadura del diseño. Notas para estudiantes molestos. Buenos Aires: Wolkowicz Editores.

Fenstermacher, G. (1989) “Tres aspectos de la filosofía de la investigación sobre la enseñanza” en Wittrock, M. La investigación en la enseñanza. Tomo 1. Madrid, Barcelona: Paidós, M.E.C.

Frascara, J. (2015). Diseño gráfico para la gente. Buenos Aires: Infinito.

Frascara, J. (2018). Enseñando diseño. Buenos Aires: Infinito.

Gardner, H. y Davis, K. (2014). La Generación App. Barcelona. Paidós.

Gráffica.info (2015). Adobe Capture CC, la app que captura los tonos cromáticos de tu entorno. Recuperado el 30 de agosto de 2018 de: https://graffica.info/adobe-capture-cc/

Gráffica.info (2016). ¿Qué es Material Design y en qué consiste Material.io? Recuperado el 30 de agosto de 2018 de https:/graffica.info/que-es-material-design-y-material-io/

Heskett, J. (2005). El diseño en la vida cotidiana. Barcelona: GG.

Hidalgo, M. en disenosocial.org (2013). Consideraciones de Diseño Social En Positivo (EN+). Recuperado el 30 de agosto de 2018 de: https://disenosocial.org/diseno-social-concepto/

Manzini, E. (2015). Cuando todos diseñan. Una introducción al diseño para la innovación social. Madrid: Experimenta Editorial.

Material design (2018). Design. Create intuitive and beautiful products with Material Design. Recuperado el 30 de agosto de 2018 de: https://material.io/design/

Marina, J. y Marina, E. (2013). El aprendizaje de la creatividad: la creatividad, el oficio y el arte de vivir. Buenos Aires: Ariel.

Mazzeo, C. (2017). Diseño y sistema. Bajo la punta del iceberg. Buenos Aires: Ediciones Infinito.

García, M. (2018) Diseñar. Recuperado el 30 de septiembre de 2018 de: https://www.garcia media.com.ar/

Guerrini, S. (2017). Los poderes del diseño. La construcción de imágenes y marcas entre culturas. Políticas y negocios. Teoría, metodología y práctica. Buenos Aires: Tropecomunicación.

Ledesma, M. y López, M. (2010). El diseño gráfico, una voz pública. De la comunicación visual en la era del individualismo. Buenos Aires: Wolkowicz Editores.

Ledesma M. y López, M. (2018). Retóricas del diseño social. Buenos Aires: Wolkowicz Editores.

Pantone Studio. Seamlessly harmonize Pantone color into your design workflow. Recuperado el 1 de octubre de 2018 de: https://www.pantone.com/studio

PUCE, Repositorio Tesis Grado y Posgrado. Recuperado el 7 de octubre de 2018 de: http:// repositorio.puce.edu.ec/

Schön, D. (1998). El profesional reflexivo: como piensan los profesionales cuando actúan. Barcelona: Paidós.

Serres, M. (2013). Pulgarcita. Buenos Aires: Fondo de Cultura Económica.

Sexe, N. (2001). Diseño.com. Buenos Aires: Paidos.

Zimmermann, Y. (2002). Del diseño. Barcelona: GG. 
Verón, E. (1987). La semiosis social. Barcelona: Gedisa.

\begin{abstract}
: the teaching of the design must be adjusted to the realities of the current student, transform the thought of the teacher designer issuer of basic concepts and fundamentals in a supplier of means to structure the experience through cases and projects, in order for the student to awaken your ability to learn and develop skills such as planning and creativity. The strategy is to be channelled through Social Design projects for vulnerable groups, with the aim of awakening interest in society and ensure that students leave their technological bubble and comfort zone. All of this with the planned work of the use of technology and new media close to students, and achieve their adequate to persuade them to use and application, thus linking the academic projects as a motivator for the teaching process of Graphic Design and the inclusion of mobile applications as tools to develop the design method.
\end{abstract}

Keywords: Social Design - teaching of design - good teaching - creative personality - applications for designers - Innovative Thinking - signification of messages.

Resumo: $\mathrm{O}$ ensino do design deve ser ajustado às realidades do atual aluno, transformar o pensamento do professor designer emitente de conceitos básicos e fundamentos em um fornecedor de meios para estruturar a experiência através de casos e projectos, para que o aluno desperte a sua capacidade de aprender e desenvolver habilidades como planejamento e criatividade. A estratégia está a ser canalizado através de projectos de Design Social para grupos vulneráveis, com o objectivo de despertar o interesse da sociedade e assegurar que os alunos deixe sua bolha tecnológica e zona de conforto. Tudo isso com o trabalho planejado da utilização da tecnologia e os novos meios de comunicação perto de estudantes, e alcançar a sua adequada para persuadi-los a utilização e aplicação, de modo a associar a projetos acadêmicos como um motivador para o processo de ensino do design gráfico e a inclusão de aplicativos móveis como ferramentas para desenvolver o método de projeto.

Palavras chave: Design Social - Ensino de design - o bom ensino - personalidade criativa - Aplicações para designers - Pensamento inovador - significação das mensagens.

[Las traducciones de los abstracts fueron supervisadas por el autor de cada artículo] 